\title{
Missed Dose
}

National Cancer Institute

\section{Source}

National Cancer Institute. Missed Dose. NCI Thesaurus. Code C50429.

A dose of medicine that was not taken at the prescribed dosing interval. 